\title{
A Welcome from the Editor
}

It is with great pleasure that I write these words to introduce this inaugural issue of the European Pharmaceutical Law Review. In 2015, the European Union celebrated 50 years of pharmaceutical legislation and the European Medicines Agency celebrated its $20^{\text {th }}$ birthday. Notwithstanding the significant history of European integration in the regulation of pharmaceuticals, this specific area of law is still characterised by a remarkable multi-levelness. The competences for various procedural as well as substantive regulatory aspects are divided over the Member States and the Union. This creates a complex regulatory web, requiring a forum that allows for discussion of the latest developments in national as well as European pharmaceutical law and policy. The EPLR will provide this forum.

We are bringing together academics, practitioners and stakeholders with an interest in pharmaceutical law and policy. In a quarterly rhythm, we will facilitate the discussion and exchange of information on national and European developments in the regulation of pharmaceuticals. As rapid technological advances require regulatory responses balancing the need for competitiveness and innovation with concerns of public health and safety, there will certainly be a lot of space for fruitful discussions. Amongst other issues, topics like biosimilars, personalised medicines as well as the growing digitalisation in the governance of pharmaceuticals will certainly provide many opportunities for analysis and debate.

Pharmaceutical law is a multi-faceted field and often goes hand-in hand with broader questions of competition law, intellectual property law, institutional and substantive EU law, to name just a few. An excellent example of this is our first-ever lead article, written by Stefano Barazza. In his article Barazza focuses on pay-for-delay agreements, while paying specific attention to the ruling of the General Court in the Lundbeck case. As the Commissions 'three step test'- approach to fining such agreements under Article 101 TFEU received the support of the General Court, the author critically analyses the interaction of competition law and intellectual property rights in these cases.

In the process of developing this journal, we came to the conclusion that the EPLR should provide a space for extensive discussions in the form of academic articles, while also leaving room for shorter, but still substantial insights into national and European developments in the form of thematic reports. In this inaugural issue, the reports provide an insight into national practices in two important fields of pharmaceutical law.

The first field covered is the increasingly required transparency of relations between pharmaceutical companies and health-care professionals, a development that can be 
observed in several EU member states. The report of van Keymeulen and Carmeliet discusses the 'Sunshine Act' in the Belgian Health Law, which recently entered into force. The act contains an obligation for annual reports of companies in the pharmaceutical and medical devices sector to report any premiums and benefits in money and in kind granted to healthcare professionals. In Denmark, the Affiliations Regulation entails a reporting obligation for healthcare professionals and even requires prior permission from the Danish Medicines Agency for the affiliation with the pharmaceutical industry under certain circumstances.

The second field addressed in the reports section is the pricing of medicinal products, with reports addressing current developments in Austria and Germany. With DG SANTE having identified the achievement of greater cost-effectiveness as one of the key challenges in its Strategic Plan 2016-2020, this discussion is very timely. Raschhofer discusses the Austrian amendments to the reimbursement of medicinal products under the General Law on Social Security, raising questions with regard to their compatibility with the objective of the Transparency Directive1989/105/EEC. In Germany, the practice of 'mixed pricing' of medicinal products has recently been challenged successfully in a ruling of the Social Court of Berlin-Brandenburg. Stallberg in his report discusses the flaws he identifies in this ruling and its practical consequences.

In our case note section, Marco Rizzi provides a detailed discussion of the judgement of the Court of Justice in case C-219/15 Elisabeth Schmitt v. TüV Rheinland, critically examining the reluctance of the Court to take a firm stance on the question of liability of notified bodies exercising regulatory functions under the medicinal products Directive 93/42/EC. Finally, we provide summaries of selected recent judgments by the Court of Justice of the European Union and introduce selected recent legislative and regulatory developments on the EU level.

At this point, I would like to thank the scholars and practitioners who have kindly agreed to serve on the Editorial Board of the EPLR, contributing their expertise and their time. Moreover, I would like to thank the fantastic staff at Lexxion that have helped conceptualise and produce this journal: Olga Hog, Nelly Stratieva and Jakob McKernan have been a tremendous support. Finally, I would like to thank Wolfgang Andreae for entrusting me with the role of Managing Editor.

I would like to conclude this editorial, by asking you to join our discussion! We are looking forward to your articles, reports and case notes. Of course we welcome any feedback on this inaugural issue and hope it proves to be valuable addition to the discussion! 